\title{
Motivating High School Students to Score Proficient on State Tests
}

\author{
Sarah Lee Brown \\ Correspondence: Sarah Lee Brown, Concord University and University of Phoenix, USA \\ Received: February 26, 2015 \\ Accepted: March 17, 2015 Online Published: March 20, 2015 \\ doi:10.11114/jets.v3i3.700 \\ URL: http://dx.doi.org/10.11114/jets.v3i3.700
}

\begin{abstract}
The researcher interviewed two groups of eleventh grade students, in a rural Appalachian setting, who tended to score low on the state mandated high stakes/low stakes test to discover their efforts on the test, specifically in reading, and to obtain their opinions concerning the effects of a specific incentive or consequence. Before the eleventh grade test, the first group of students was asked if they had or had not tried to do well on the tenth grade test and if they had not tried to do well, what would motivate them to try on the eleventh grade test. After the eleventh grade test, the second semester group of eleventh grade students was asked if they had tried on the eleventh grade test and why or why not and if they had tried on the tenth grade test the previous year. Responses from both groups of students indicated incentives or consequences would make or had made a difference in their motivation to try on the test. While almost $35 \%$ of the students indicated they had not tried to do their best on the tenth grade test before the incentive, $100 \%$ of the second semester students indicated after the incentive, they had tried to do their best.
\end{abstract}

Keywords: high stakes testing, student motivation, incentives, consequences

\section{The Issue}

When there are no consequences for the students, how to motivate them to score well on state high stakes testing is a problem that school districts must solve, because even when there are no personal high stakes, the consequences of the students' lack of effort may mean a loss of funding, corrective action, restructuring, or complete take-over of the school (what are the consequences, ed.gov). Some districts have resorted to providing incentives in many forms including electronics, gift cards, and additional credit (Kuznia, 2012), while others have chosen to use consequences such as retention of students (Rose, 2012) or failure to graduate (Cole \& Osterlind, 2008) in order to increase motivation to do well.

The purposes of this study were two-fold. First, the administration hoped to determine if first semester eleventh grade students in a small school district in the southeastern part of the United States had tried on the state-mandated high-stakes for schools, low-stakes for students test as tenth graders and if not, what would motivate them to do well on the state test as eleventh grade students. The second purpose was to determine, once the test was given to the eleventh grade students, if because of an incentive/consequence, the students who had not tried on the tenth grade test tried on the eleventh grade test.

At the time of the study, the researcher was the curriculum director for the district and as part of the duties, was responsible for analyzing situations and helping to solve critical issues facing the schools. Students at this particular high school had a reputation for not doing well on the state test. In this state, the stakes for students are not high on the test, but they are very high for schools. In schools where students do not score proficient, there is a constant concern of being placed upon improvement status. In this school, the administration was considering enforcing consequences for those who scored poorly on the tests and providing incentives for the students who did well. In the first semester, the students were not aware of a plan by the administration to enforce consequences in that school year based upon the current year's test scores nor of the plan to provide incentives in the upcoming year for those students who scored well on the test. Hoping to encourage greater student achievement on the tests, it was important for the administration to learn the attitudes of the students concerning the test and what would encourage them to do their best on the test. In addition, after the test was taken, it was important to the administration to know if the incentive/consequence plan had worked in motivating the students to do their best on the test. The administration believed an increase from tenth grade to eleventh grade in the percent of students scoring proficient on the test would lend support to the incentive plan implemented by the school and district.

The information gained from the study was significant for the school and district administration in that it helped them to 
better understand student motivation concerning the test in this particular high school. The information could be important to other high schools facing similar motivation issues where students are not giving their best efforts on the tests.

\section{Literature Review}

Student's effort in scoring well on state-mandated high and low stakes testing has been the subject of previous studies and articles. Cole, Bergin, and Whittaker (2008) reported when students do not find the results of the test to be important or the test to be useful, they do not put forth their best effort. Thelk, Sundre, Horst, and Finney (2009) noted that unmotivated students who took computer-based tests clicked through the questions without spending adequate time to get the answers correct. The authors also noted in testing situations, when the stakes went up, so did the effort put forth by the students and their perception of importance of the test also increased. In a study involving college students, Cole and Osterlind (2008) reported the consequences of the test did matter to the students. They found it likely that student performance on low-stakes testing would not be as high as it would be if the test were high stakes for the individual.

Sometimes the question is concerned with whether or not the students have the knowledge to be successful on the test. According to Wise and DeMars (2005), the test scores of students who do not do their best on the tests are deceptive concerning the knowledge, ability, and skill of the students. When tests have high stakes for the schools but low stakes for the individual students, it may not be important to the students to do their best to show what they know (Abdelfattah, 2010). In other cases, it may be evident from classroom assessments that the students know the materials covered, but they fail to put their knowledge to use when it comes to the testing. In some of these cases, the students feel their efforts are not important because the results of the tests do not matter for the individual even though the tests are high stake tests for the school (Wise \& DeMars, 2010).

The literature specifically concerning what schools can do to encourage students in non-high stakes states to do well on the state-mandated tests is limited. Supon (2008) provided a list of ideas to encourage students to do well on the tests generated from both teachers and principals. Included in the lists were strategies such as teaching test taking skills, providing the suggested tools for the students, giving students pencils with motivational slogans, and sending newsletters to parents. Wise (2009) noted appealing to the academic citizenship of the students or providing more substantive feedback to the students after the test as possible solutions while Wise and DeMars (2005) suggested imposing consequences and providing incentives may have an effect on effort.

There is literature supporting the linking of effort to motivation. Bandura (1990) described three classes of motivators. According to Bandura, the second set of motivators is based on social incentives and involves pleasant and unpleasant experiences. Bandura noted in order to gain approval or to avoid disapproval, people will act in certain ways. In order for praise and disapproval to have a real effect, they must be backed up by tangible effect or consequences.

Abdelfattah (2010) conducted a study of $9^{\text {th }}$ grade students concerning their performance on low-stakes examinations in math and science. Abdelfattah found a significant correlation between motivation and the test scores. Student who were more motivated to take the exams scored higher.

\section{Theoretical Framework}

Smith and Holterman ten Hove (2009), noted the relationship between consequences and effort on exams. The authors noted the consequences of an exam affect the amount of effort students will put forth on the assessment as a whole and even on individual items on the assessment. If the consequences are not high enough, the students may choose to not complete the items. According to the researchers, the motivation and effort are directly related to the level of the consequence.

It is this motivational theory that provided the framework for the questions proposed to the students and for the study. Based upon this theory, students may be motivated by higher consequences to do better on their tests. In like manner, a lack of high level consequences may result in students not putting forth the necessary effort in order to do well. The survey questions were designed to understand the motivation of the students to do well on the high stakes test. By providing the survey in a verbal face-to-face manner, the researcher was able to gain more information from the students and students were able to feel that the school and district were willing to listen to their ideas and concerns.

\section{Method}

Both qualitative and quantitative methods were used in the study. In the qualitative part of the study, interviews were conducted to learn if the students had tried on their tests and if not, what was likely to motivate them to try on future high stakes state testing. In the quantitative portion of the study, a comparison was made for each eleventh grade student between the scores obtained on the tenth and eleventh grade state-mandated tests. Averages were obtained and percentages were calculated. 


\subsection{Participants}

The participants in the interview part of the study were 71 eleventh grade students who had taken the state-mandated standardized test as tenth graders and who would be taking or had already taken the test as eleventh graders. In an effort to reach all eleventh grade students and as a means of convenience and lack of disruption to the school, the students were divided into two groups, those who had English first semester and those who had English second semester. One teacher taught all of the students and was willing to cooperate with the researcher in allowing each student time to meet and respond to the questions. The students in the first semester were asked questions concerning if they had tried on the test in tenth grade and if not, what would have encouraged them to try. The students in the second semester had already taken the eleventh grade test when questioned. They were asked if they tried on the test in tenth grade and if they tried on the test in eleventh grade. If they had not tried in tenth grade but tried in eleventh grade, they were asked why they tried in the eleventh grade. If they tried in both grades, they were asked if the incentives implemented by the administration made a difference in the amount of effort. Scores on the state-mandated tests were included in the final data analysis for an additional five students who did not participate in the interview process.

\subsection{Research Questions}

Students in this rural Appalachian school have a reputation for not scoring well on the state-mandated assessment. Teachers and administrators in the county believed the students had the ability to score well, but were not trying. Administration was ready to implement an incentive plan for the upcoming test, but the students were not aware of the plan. The research questions were: 1) Would an incentive/consequence plan work in motivating students to do better on the state high stakes test? 2) Did the newly implemented incentive/consequence plan work in motivating students to do better on the high stakes test?

\subsection{Research Design}

The study was designed using the interview method with a survey. All students in the eleventh grade English class were invited by their teacher to meet with the district office representative to respond to set survey questions concerning their school work. Students were sent from the classroom individually to the interview in the English office. Students were allowed to refuse the interview if they so chose. They were allowed to answer some or all of the questions. In some cases, responses led to additional questions not covered by this research. Students were free during the interview to discuss any ideas concerning why the school's test scores were generally low.

\subsection{Data Collection}

During the first semester of their eleventh grade year, 28 students were interviewed. During the second semester of their eleventh grade year, 43 students were interviewed. Students were sent from their English classroom to the English office where they were greeted by name and made to feel comfortable. Most of the students had seen the interviewer in the school on numerous occasions and appeared to be at ease in responding to the questions.

The researcher explained to the students how their school's test scores were low and that the purpose was to find out why scores were low and what the school could do to help the students do better on the test. Student answers were placed into a spread sheet on the computer. After the scores on the eleventh grade state-mandated test were received, a comparison of the student's eleventh grade score was made to the same student's tenth grade score. Another spread sheet was created in which the student names were replaced by numbers to ensure confidentiality. On this spread sheet the tenth and eleventh grade scaled scores were compared with each other and a comparison was made to see if those who did not try on the tenth grade test improved in scaled score on the eleventh grade test.

\subsection{Interview Questions}

First and second semester students were asked different questions due to the situation. First semester students had not taken the eleventh grade state-mandated test. Second semester students had taken the eleventh grade state-mandated test. After the first semester students were interviewed, but before they were tested in eleventh grade, the administration instituted an incentive/consequence plan in which students who did not score proficient on the eleventh grade test would be required to take a special class as seniors and those who did score proficient would be allowed to opt out of senior exams in the subjects in which they scored proficient. In addition, these students could choose elective classes while their peers were in the extra help classes.

First semester students were asked: Did you try on the tenth grade state test? If the response was negative, the student was asked: How can we encourage you to do better? If the response to the first question was positive, the student was then asked: How can we encourage your friends to do better on the test? Second semester students were asked two questions: 1) Did you try on the tenth grade state test? 2) Did you try on the eleventh grade test? If the response to the first question was no and the response to the second question was yes, the next question was: Why did you try? If the responses to both the first and second questions were yes, the next question was: Did the incentive encourage you to do 
better?

\subsection{Data Analysis}

Full data analysis could not take place until the results of the state-mandated test were received by the district, but upon completion of the first semester interviews, the responses were reviewed to see if the decision being made by the administration to implement consequences and incentives was in the right direction. After the second semester interviews, the responses were again reviewed to see if the implementation of the consequences and incentives had made a difference in the efforts of the students. Final analysis was done after the scores on the state-mandated test were received to see if the implementation of the consequences and incentives had motivated the students to try and had thus made a difference on the actual scores.

\section{Results}

The results of the study were collected in three settings. In the first round, the results from the first semester students were analyzed. Next, the results from the second semester students were reviewed. Finally, when the test scores were received, student responses were compared to the test scores.

\subsection{Statistics and Data Analysis of First Semester Students}

The findings are based upon the three separate analyses of the data. Of the 28 first semester students interviewed, 13 or $46 \%$ responded to the question concerning if they tried on the tenth grade state-mandated test. Of the 13 responding students 6 or $46 \%$ did not try to their fullest ability.

Of the 28 first semester students, 20 or $71 \%$ responded to the question concerning how we can encourage students to do better on the test. Their responses are in the table below. Of the 20 who responded, 10 or $50 \%$ indicated the addition of incentives would encourage students to do better.

Table 1. How Can We Encourage Students to Score Proficient on the Test?

\begin{tabular}{lll}
\hline Number of responses & Comment & Percent \\
\hline 1 & Have better teachers & 5 \\
1 & Need to know how to do the work & 5 \\
1 & Less lazy students & 5 \\
1 & Threaten us & 5 \\
1 & More prep time & 5 \\
1 & Get stricter & 5 \\
2 & Have a special class & 10 \\
1 & Talk up the test & 5 \\
1 & Listen to music while we test & 5 \\
10 & Provide incentives/consequences & 50 \\
\hline
\end{tabular}

Summary of student responses concerning what the school could do to motivate students to do better on the state test

\subsection{Statistics and Data Analysis of Second Semester Students}

Of the 43 second semester students, 42 or $98 \%$ responded to the question concerning if they tried on the tenth grade state-mandated test. The same $98 \%$ responded to the question concerning if they tried on the eleventh grade test. Thirteen or $31 \%$ of the 42 second semester responding students indicated they had not tried to their fullest ability on the tenth grade test, but $100 \%$ of the responding students indicated they did try on the eleventh grade test. When the 13 were asked why they tried on the eleventh grade test but had not tried on the tenth grade test, $100 \%$ responded it was due to the incentives. When the 29 students who responded they had tried in both tenth and eleventh grade were asked if they believed the incentive policy being implemented by the administration had caused students to try harder on the test, 27 students replied. Of the 27 responses, 21 or $77 \%$ said yes, $7 \%$ said maybe, and $4 \%$ said somewhat, for a total of $88 \%$ positive response toward the incentive. One student indicated a belief that the incentives did not make a difference to all students and one student emphatically stated the incentives would not make a difference.

\subsection{Statistics and Data Analysis from Comparison of Scores}

A comparison was made of each eleventh grade student's eleventh grade and tenth grade scores. Scaled scores for all students including those who did not participate in the interviews were compared. Scores for 76 students were compared.

Of the students who indicated they did not try on the test in the tenth grade, scores for 15 of them were available. Of the 15,13 did not master the reading test in the tenth grade. Of those 13, 7 mastered the reading test in the eleventh grade and the 6 who did not master showed improvement in the eleventh grade scaled score over the tenth grade score. Twenty of the 76 students for whom two years of data were available did not improve from tenth to eleventh grade, but of the 20, 7 mastered the reading portion of the test. 
Of the 76 students for whom data was available from tenth to eleventh grade, 30 or $39 \%$ mastered the reading part of the state test in tenth grade. In eleventh grade, of those same students 43 or 57\% mastered the reading portion of the test for an increase in $18 \%$ mastery. Of the 76 students, 56 or $74 \%$ showed improvement in eleventh grade over their tenth grade scaled scores.

\section{Discussion}

From the results, the first semester students who were interviewed were of the belief that adding an incentive or consequence would encourage students to do better on the state-mandated test. The school added the incentive before the eleventh grade test was given. The incentive/consequence added by the school was that students who did well on the test did not have to take their final exam in the next school year on the subjects in which they did well and those who did not do well were to be placed in a remedial course to help them learn the content. For these students, the incentive would mean if they did well in eleventh grade, they would be exempt from exams in the tested areas as seniors. If they did not do well as eleventh grade students, they would be required as seniors to take remedial courses while their friends were in elective classes.

For the second semester students who were aware of the incentives and had already taken the test before their interviews, the students were relatively certain the incentive was effective. For those students who had not tried in tenth grade, the incentive had encouraged them to do their best. If they had tried in tenth grade, several of them indicated the incentive encouraged them to do even better. Many of the students indicated a belief that the incentive had helped their friends to try harder on the test.

The test scores themselves are evidence that something happened between tenth and eleventh grade for these students. Several of the students earned mastery on the reading portion of the test and others improved from the previous year. The improvement in test scores was enough to cause this particular high school to continue to implement the incentive/consequence plan for the upcoming year.

The dual purpose of this study was to discover if students had tried on their tenth grade state-mandated test and if they had not tried, would an incentive motivate them to try. The results of the study indicated some students had not previously tried on their tests, many students believed an incentive would encourage them to try, and after implementation of the incentive by the administration, most of the students tried to master the assessment. Enough students either mastered the assessment or improved to the point the school and district administration has chosen to continue the incentive/consequence plan.

Based upon the student responses both before and after the state-mandated test, it appears adding the incentive of not having to take the end of course exam in a subject for which the student achieves mastery or being placed in a remedial course for extra help in subjects not mastered while peers are in elective classes was an effective move on the part of the administration. Schools and districts may want to consider adding incentives or enforcing consequences in order to encourage students to put forth more effort on the state tests.

While the results of this brief study are applicable to the high school in which it was conducted, many schools across the state and nation have the same concerns with students who are not mastering the state high stakes tests. The school where this study was conducted implemented an incentive/consequences program and the students indicated the program provided the motivation for them to put forth more effort on the high stakes test. Other schools and districts might benefit from examining their own incentives/consequences and asking their own students what would encourage them to do better on the test. The district where this study was conducted might profit from looking at the same issue in a few years to see if the incentive program is still working or if changes are needed in order to continue encouraging the students to meet the necessary standards for proficiency. In addition, this district might look at the other possible recommendations given by the students for increasing test scores.

\section{References}

Abdelfattah, F. (2010). The relationship between motivation and achievement in low-stakes examinations. Social Behavior and Personality, 38(2), 159-167. http://dx.doi.org/10.2224/sbp.2010.38.2.159

Bandura, A. (1991). Self-regulation of motivation through anticipator and self-reactive mechanisms. In R. A. Dienstbier (Ed.), Perspectives on motivation: Nebraska symposium on motivation (Vol. 38, pp. 69-164). Lincoln: University of Nebraska Press. http://www.uky.edu/ eushe2/Bandura/Bandura1991Nebraska

Braden, J. P. (2004). High-stakes testing and no child left behind: Information and strategies for educators. MD: National Association of School Psychologists.

Cole, J. S., Bergin, D. A., \& Whittaker, T. A. (2008). Predicting student achievement for low stakes tests with effort and task value. Contemporary Educational Psychology $33 \quad$ (208) 609-624. 
http://dx.doi.org/10.1016/j.cedpsych.2007.10.002

Cole, J. S., \& Osterlind, S. J. (2008). Investigating differences between low- and high-stakes test performance on a general education exam. The Journal of General Education, 57, 119-130. http://dx.doi.org/10.1353/jge.0.0018

Greatschools staff. High school exit exams: Issues to consider. http://www.greatschools.org/students/academic-skills/587-high-school-exit-exams-issues.gs?page=all

Kuznia, R. (2012). Some schools offer incentives to students to improve state test scores. The LA Daily News. http://www.dailybreeze.com/general-news/20120427/some-schools-offer-incentives-to-students-to-improve-state-t est-scores

Lee, J. (2010). Dual standards of school performance and funding? Empirical searches of school funding adequacy in Kentucky and Maine. Education Economics, 18, 207-228. http://dx.doi.org/10.1080/09645290902796415

Monohan, T. (1998). The rise of standardized educational testing in the U. S.: A bibliographic overview. http://publicsurveillance.com/papers/testing.pdf

Nichols, S. L., \& Berliner, D. C. (2007). Collateral damage: How high-stakes testing corrupts America's schools. Cambridge, MA: Harvard Education Press.

Rose, S. (2012). Third grade reading policies. Education Commission of the States. http://www.ecs.org/html/Document.asp?chouseid=10347

Smith, L. F., \& Holterman ten Hove, K. (2009). A multimethod examination of university students' view of assessment. In D. M. Mcinerney, G. T. L. Brown, \& A. D. Liem (Eds.) Student Perspectives on Assessment: What students can tell us about assessment for learning. (pp. 207-231).

Stronger accountability testing: Frequently asked questions. http://www2.ed.gov/nclb/accountability/ayp/testing-faq.html

Supon, V. (2008). High-stakes testing Strategies by teachers and principals. Journal of Instructional Psychology, 35(3), 306-308.

Thelk, A. D., Sundre, D. L., Horst, S. J., \& Finney, S. J. (2009.) Motivation matters: Using the student opinion scale to make valid inferences about student performance. The Journal of General Education, 58 (3), 128-152. http://130.102.44.246/login?auth=0\&type=summary\&url=/journals/journal_of_general_education/v058/58.3.thelk. html 10.1353/jge.0.0047

What are the consequences of not making adequate yearly progress (AYP)? https://answers.ed.gov/link/portal/28022/28025/Article/575/Schools-not-making-adequate-yearly-progress

Wise, S. (2009). Strategies for managing the problem of unmotivated examinees in low-stakes testing programs. The Journal of General Education, 58(3), 12-168. http://muse.jhu.edu/journals/jge/summary/v058/58.3.wise.html 10.1353/jge.0.0042

Wise, S. L., \& DeMars, C. E. (2005). Low examinee effort in low-stakes assessment: Problems and potential solutions. Educational Assessment, 10(1), 1-17. http://dx.doi.org/10.1207/s15326977ea1001_1

Note: Some form of testing for school children has been in effect since at least the 1840s (Monohan, 1998). Since the passing of the No Child Left Behind Act (NCLB) of 2002, the majority of public schools have been involved in the testing process (stronger accountability). While the stakes are high for all schools and states, in some states, the stakes for individual students are much higher than in others. NCLB does not require states to base promotion, retention, or graduation upon the test scores (Braden, 2004), but in some states including Florida, Texas, and Virginia passing of a test is necessary in order to graduate (Greatschools Staff). In other states, such as Maine (Lee, 2010) and West Virginia (Greatschools Staff), while students are required to take the test, student risks are much lower or non-existent. According to Nichols and Berliner (2007), stakes are considered to be high for the students because of the significance of the consequences, so if there are no perceived consequences, the stakes are low.

When students perceive the personal stakes to be low on the test, they may not be motivated to do their best work. Lack of student motivation to do well on the test may then lead to lower scores for a school and result in the same test being high stakes for the school or district. If students can be motivated to do well on the test, not only may the students benefit from the higher score, but the school or district may avoid being placed on improvement status.

\section{(cc) $\mathrm{BY}$}

This work is licensed under a Creative Commons Attribution 3.0 License. 